\title{
Application of Accelerated Learning in Teaching Environmental Control System in Qassim University
}

\author{
Tomas U. Ganiron Jr. \\ College of Architecture, Qassim University, Buraidah City \\ tomas@qec.edu.sa
}

\begin{abstract}
This paper presents findings based on the adoption of the principles of Accelerated Learning in Environmental Control System course of the College of Architecture, Planning and Design, Qassim University, Buraidah City. The results of the study suggest the effectiveness of Accelerated learning as indicated by the following: the students' active participation in class individual and group activities, their good performance in midterm and final examinations and ability to apply what they had learned in environmental control system for their area of specialization in architecture, planning and design. As this study is based on classroom instruction of Environmental Control System, the change in behavior expected is the increased ability of the architecture students to perform the core plus the additional requirements of the course.
\end{abstract}

Keywords: Accelerated learning, educational management, engineering education, multiple intelligences

\section{Introduction}

Learning in a structured educational setting may be thought of as a two-step process involving the reception and processing of information. In the reception step, external information (observable through the senses) and internal information (arising introspectively) become available to students, who select the material they will process and ignore the rest. Learning in a structured educational setting may be thought of as a two-step process involving the reception and processing of information. In the reception step, external information (observable through the senses) and internal information (arising introspectively) become available to students, who select the material they will process and ignore the rest. The processing step may involve simple memorization or inductive or deductive reasoning, reflection or action, and introspection or interaction with others [1]. The outcome is that the material is either "learned" in one sense or another or not learned.

Research reveals that Accelerated Learning (AL) techniques can enhance retention and lead to improved performance.

Many educationalists have been working on the most effective approaches to classroom teaching. In America the Accelerated Schools program was established, aimed particularly at improving education for at-risk students [2]. The term "accelerated learning" is used, sometimes fairly loosely, to indicate modern research-based approaches to learning, drawn from a wide range of fields such as neuro-science, psychology, and learning theory. The technique is grounded in an understanding of how learning takes place, rather than what is to be learned. The principle is that with the correct teaching and motivation, and a positive learning environment, learners are able to achieve beyond expectations [1,2]. 
As this study is based on classroom instruction of Environmental Control System course, the change in behavior expected is the increased ability of the students to perform the core plus the additional requirements of the course.

The Bachelor degree course in Architecture is a 4 year course consisting of 139 credit-hours. At the Qassim University, the educational system in the college is based on two main semesters per educational year. Each semester is fifteen (15) weeks length. In addition; an optional eight week summer semester may be offered. An architecture student may complete any of the architecture programs in 8 semesters after the Preparatory Year Program (PYP) [2, 13]. A successful architecture student may complete the full requirements of the selected program if he completed (after the PYP) a total of 139 credit-hours.

One of the engineering courses in Architecture is Environmental Control System, a 2-unit subject offered in level 4 of fall semester. Environmental Control System is the capstone course in architecture since it presents the basic principles for the selection and the design of the main environmental control systems in buildings, including plumbing, heating, ventilation, air conditioning, electric, protection systems.

This course has traditionally been delivered through classroom multimedia instruction to architecture students. One semester learning period is insufficient to fully discuss all the topics for this course.

The adoption of the principles of Accelerated Learning benefited the students in that they learned more, faster, and better, were able to apply what they learned in class in working on their projects, and became better and more creative innovators [4].

Among the techniques used in the course, lectures with the aid of an LCD have been weak in tapping a number of intelligences. This implies that although its use may lead to higher efficiency, the learner may find it difficult to be fully attentive, hence may not learn as much as expected.

The use of the other techniques such as individual and group activities is more involving and fun to the students. The learning facilitator noted that mapping out the intelligences for each instruction technique allows one to be more aware of the distinctions among the students with respect to their learning styles. If an instruction technique addresses most of the students' intelligences, then they learn much more at that span of time.

Therefore, this is a practice that must be adopted by an accelerated learning facilitator in his pursuit of higher efficiency. Without using AL techniques, learning facilitators could still be effective as long as they are able to catch the attention of the class through humor and fun and the use of multimedia. The learning facilitator must be open to learning from the ten (10) students' intelligence and should retain a sense of wonder that could be passed on to the students [2, 4]. In so doing, professional preparation becomes more thorough because it was more enjoyable than cumbersome

\section{Related Literature}

\subsection{Traditional vs. Accelerated Learning}

The term "traditional learner" describes a student suited to learn within the boundaries of a physical classroom using a predefined curriculum [5]. The Rochester Institute of Technology describes this as an instructor-centered environment, where the instructor controls materials and the learning pace for students to acquire and memorize knowledge [6]. 
The traditional teaching approaches are generally teacher-directed and follow cookbook steps of activities and demonstrations [7]. This approach may not provide students with valuable skills or even with a body of knowledge that lasts much beyond the end of the term. To enhance the quality of teaching and learning in the classroom accelerated learning such as active, cooperative, collaborative and problem-based learning can be utilized. However, Accelerated Learning is a spin-off from Gardner's Theory of Multiple Intelligences and Neuro-Linguistic Programming [1, 8].

Russell differentiated the traditional learning from accelerated learning [9]. These are indicated in Table 1.

\section{Table 1. Traditional versus Accelerated Learning}

\begin{tabular}{|l|l|}
\hline Traditional & Accelerated \\
\hline Linear & Nonlinear, systemic \\
\hline Knowing about & Knowing how \\
\hline Formal, structured & Informal, flexible \\
\hline Conscious & Unconscious \\
\hline Memorized facts & $\begin{array}{l}\text { Intuitive and applicable } \\
\text { knowledge }\end{array}$ \\
\hline "Have to" learning & "Want to" learning \\
\hline Hard work & Fun, effortless \\
\hline Emotion-free & Emotional \\
\hline Passive & Active \\
\hline
\end{tabular}

When it began in the 1970s, accelerated learning was revolutionary. Its starting point was so completely different from anything on offer at that time [10]. Educationalists still thought about curriculum, terms, courses and examinations. Trainers dealt in lectures, demonstrations, classes and workshops.

It suggested that: a) learners and active learning were more important than teachers and courses; b) the way people teach was out of step with the way the brain works, and; c) it was possible for learners to become much more engaged and motivated in their learning and therefore learn faster $[10,11]$.

Accelerated learning was based on the work of Georgi Lozanov, a Bulgarian medical doctor and professor of psychiatry who developed a teaching method that he called 'suggestopedia' [11, 12]. He developed program that seemed to teach young children to read significantly more quickly and gave them a better grasp of mathematics than their peers [12]. He also developed a language learning program in which learners were understand and retain much more new language than was the case with other methods. His results were validated by both Bulgarian experts and by a UNESCO team $[6,14]$.

However, no sooner had the west begun to hear of his methods than Lozanov was placed under house arrest in Bulgaria and forbidden contact with foreigners by the communist regime, which jealously guarded 'their' learning methods [12]. Those (mainly in the US) who had seen something of the method in action, did their best to make sense of it, but the result was that a lot of the early proponents missed what had actually made the difference in the learning and therefore picked up on surface details $[12,14]$. 
Early advocates of accelerated learning talked about the brain, about emotions, about learning styles and much more. It's worth remembering that the 1970s and 1980s were exciting times for learning and education [7, 11]. Not only were amazing things happening in terms of scientific discoveries, but we were also beginning to get tantalizing glimpses of the way that the human brain works.

Throughout the 1990s, as alternative therapies and developments in neuroscience arrived thick and fast, so accelerated learning has embraced many of these too $[9,10]$. In schools first, Colin Rose and then Alistair Smith have been at the forefront of helping teachers to develop imaginative approaches that involve accelerated learning.

Accelerated learning combines aspects of established learning theory with brainbased approaches, in order to engage learners and speed up the process of learning. Accelerated Learning is a spin-off from Gardner's Theory of Multiple Intelligences and Neuro-Linguistic Programming [6, 11].

\subsection{Neuro-Linguisting Programming (NLP)}

Neuro-linguistic programming (NLP) is an approach to communication, personal development, and psychotherapy created by Richard Bandler and John Grinder in California, USA in the 1970s [14]. Its creators claim a connection between the neurological processes ("neuro"), language ("linguistic") and behavioural patterns learned through experience ("programming") and that these can be changed to achieve specific goals in life. Bandler and Grinder claim that the skills of exceptional people can be "modelled" using NLP methodology then those skills can be acquired by anyone. Bandler and Grinder also claim that NLP can treat problems such as phobias, depression, habit disorder, psychosomatic illnesses, myopia, allergy, common cold and learning disorders, often in a single session $[12,14]$. NLP has been adopted by some hypnotherapists and in seminars marketed to business and government.

Reviews of empirical research show that NLP has failed to produce reliable results for its core tenets. The balance of scientific evidence reveals NLP to be a largely discredited pseudoscience. Scientific reviews show it contains numerous factual errors, and fails to produce the results asserted by proponents [11, 12]. According to clinical psychologist Grant Devilly, NLP has had a consequent decline in prevalence since the 1970s [12]. Criticisms go beyond lack of empirical evidence for effectiveness, saying NLP exhibits pseudoscientific characteristics, title, concepts and terminology as well. NLP serves as an example of pseudoscience for facilitating the teaching of scientific literacy at the professional and university level [12,14]. NLP also appears on peer reviewed expert-consensus based lists of discredited interventions. In research designed to identify the "quack factor" in modern mental health practice $[10,11]$.

2.2.1. Applications: Early books about NLP had a psychotherapeutic focus given that the early models were psychotherapists. As an approach to psychotherapy, NLP shares similar core assumptions and foundations in common with some contemporary brief and systemic practices such as solution focused brief therapy [9, 10]. NLP has also been acknowledged as having influenced these practices with its reframing techniques which seeks to achieve behaviour change by shifting its context or meaning, for example, by finding the positive connotation of a thought or behaviour. According to Stollznow, "Bandler and Grinder's infamous Frogs into Princes and other books boast that NLP is a cure-all that treats a broad range of physical and mental conditions and learning difficulties, including epilepsy, myopia and dyslexia [12]. With its promises to cure schizophrenia, depression, and post-traumatic stress disorder, NLP shares similarities 
with Scientology and the Citizens Commission on Human Rights, CCHR. "The two main therapeutic uses of NLP are: (1) as an adjunct by therapists practicing in other therapeutic disciplines; (2) as a specific therapy called Neuro linguistic Psychotherapy which is recognized by the United Kingdom Council for Psychotherapy with accreditation governed at first by the Association for Neuro Linguistic Programming and more recently by its daughter organization the Neuro Linguistic Psychotherapy and Counselling Association [14].

While the original goals of Neuro linguistic programming were therapeutic, the patterns have also been adapted for use outside psychotherapy for interpersonal communications and persuasion including business communication, management training, sales, sports, and interpersonal influence, used for coaching, team building, public speaking, negotiation, and communication [9, 14].

\subsection{Gardner's Theory of Multiple Intelligences}

In the 1970s, Howard Gardner, a professor of education at Harvard University, started questioning the traditional definition of intelligence on which such tests were based. Gardner worked with talented children and adults who had brain damage. $\mathrm{He}$ found that people had many other gifts and talents that weren't necessarily reflected in the traditional ideals of intelligence. He used a variety of sources - including neurophysiological research and studies with autistic people, geniuses, and protégés to support his model that various parts of the brain provide different types of intelligence $[1,14]$.

In 1983, Gardner published the book "Frames of Mind," which outlined seven different types of intelligence. Ten years later, he added an eighth type. This multiple intelligences (MI) theory became a popular model for understanding the many ways in which human intelligence exists $[2,14]$.

The multiple intelligences theory (MI theory) claims that all humans have eight intelligences, to a lesser or greater extent, and that each have a different intelligence profile. This profile is based on genetics and experiences, and it makes us unique from others [14]. The intelligences are as follows:

2.3.1. Linguistic intelligence: This is the ability to use spoken and written language effectively to express oneself. Lawyers, writers, and speakers tend to have high linguistic intelligence.

2.3.2. Logical-mathematical intelligence: This is the ability to analyze problems logically, work effectively with mathematical operations, and investigate issues using the scientific method. Finding patterns and deductive reasoning are other capabilities associated with this intelligence. People working in the scientific and mathematical communities tend to be high in this type of intelligence

2.3.3. Musical intelligence: Increase the resistance of concrete to frost action by introducing numerous tiny air bubbles into the hardened cement paste.

2.3.4. Bodily-kinesthetic intelligence: This is the ability to use the body for expression. People high in this intelligence use their physical coordination to master problems. Professional dancers and athletes are good examples of this 
2.3.5. Spatial intelligence: This is the ability to recognize, use, and interpret images and patterns and to reproduce objects in three dimensions. Successful architects, sculptors and designers are likely to have high spatial intelligence.

2.3.6. Interpersonal intelligence: This is the ability to understand people's intentions, motivations, and desires. This intelligence allows individuals to work well with others. Professions like therapy, teaching, and sales attract individuals with high interpersonal intelligence.

2.3.7. Intrapersonal intelligence: This is the ability to understand oneself, and to interpret and appreciate your own feelings and motivations. Therapists, actors, caregivers, and writers are all people who can bring high levels of personal awareness to their work.

2.3.8. Naturalist intelligence: This is the ability to recognize and appreciate our relationship with the natural world. Astronomers, biologists, and zoologists are examples of professions with a high level of naturalist intelligence. (This is the eighth intelligence that Gardner added, after first publication of his model.

2.3.9. Emotional intelligence: This is the ability to able to recognize an emotion as they are experiencing it, and react to it in a way that is considered positive by the culture.

2.3.10. Existential intelligence: This is the ability to know the reason for one's existence, or 'why you are here.'

Although the intelligences are anatomically separated from each other, Gardner claims that the intelligences very rarely operate independently. Rather, the intelligences are used concurrently and typically complement each other as individuals develop skills or solve problems $[2,12]$. For example, a dancer can excel in his art only if he has 1) strong musical intelligence to understand the rhythm and variations of the music, 2) interpersonal intelligence to understand how he can inspire or emotionally move his audience through his movements, as well as 3) bodily-kinesthetic intelligence to provide him with the agility and coordination to complete the movements successfully.

Gardner argues that there is both a biological and cultural basis for the multiple intelligences. Accepting Gardner's Theory of Multiple Intelligences has several implications for teachers in terms of classroom instruction.

As the theory states that all intelligences are needed to productively function in society and teachers, Therefore, it should think of all intelligences as equally important. This is in great contrast to traditional education systems, which typically place a strong emphasis on the development and use of verbal and mathematical intelligences.

It also implies that teachers should structure the presentation of material in a style that engages most or all of the intelligences.

All students will come into the classroom with different sets of developed intelligences. This means that each child will have his own unique set of intellectual strengths and weaknesses. These sets determine how easy (or difficult) it is for a student to learn information when it is presented in a particular manner, which is commonly referred to as a learning style. Defined were the visual, auditory and 
kinesthetic intake styles. Many learning styles can be found within one classroom. As children do not learn in the same way, they cannot be assessed in a uniform fashion.

Traditional tests (e.g., multiple choice, short answer, essay...) require students to show their knowledge in a predetermined manner. Supporters of Gardner's theory claim that a better approach to assessment is to allow students to explain the material in their own ways using the different intelligences. Preferred assessment methods include student portfolios, independent projects, student journals, and assigning creative tasks $[3,11,15]$.

\section{Methodology}

Environmental Control System is a course taken by the regular third year Architecture students in Qassim University This course was chosen by the researcher as a pilot course for the implementation of AL due to the following reasons:

1. The course content - much material is to be covered in one term;

2. The requirements of the course - the course requires involvement in critical skills to raise clear and precise questions, use abstract ideas to interpret information, consider diverse points of view, reach well-reasoned conclusions, and test them against relevant criteria and standards;

3. The nature of the course - the course is mathematical or quantitative than other architecture courses but tests more the creativity of the students; and

4. The difficulty in impressing upon the students the importance of safety, considering that since it is usually perceived as a practical subject matter that could easily be learned in the course of one's work experience in industry, the tendency of students is to take safety for granted.

The researcher taught this course for three consecutive terms and gradually developed an instructional approach using the guidelines and principles of Accelerated Learning.

\subsection{Instruction Techniques}

The following instruction techniques used are: 1). film showing of the different kinds of hazards and tips on safety in the workplace, 2). lectures with the aid of LCD projector, 3). individual and group activities to facilitate learning, 4). study of a model company that could be benchmarked for safety program implementation, 5). study of an adopted company, an SME to which the new learning about safety management could be applied and 6) presentation of particular topics by the students within the grasp and understanding of the class.

\section{Insights obtained from the adoption of Accelerated learning}

The following observations were found in the experimental classes. 1) The various activities appeal to a majority of the intelligences, 2). The film on hazards in the workplace appealed to the visual and auditory students. The requirement to make a group reaction paper appealed to the kinesthetic, 3). The group presentations appealed to the three intake styles, a sign that the students adopted AL principles although unintentionally and probably, intuitively, 4) The safety programs designed by the students for their "adopted companies" were comprehensively written documents in the form of manuals, graphic safety visuals depicting pain when meeting an accident, and 
safety orientation videos (with musical background during pauses) for employees and 5) The students who were not aware of AL principles performed ably as effective learning facilitators in their group presentations. The techniques they used bore the characteristics of AL as shown on Table 1.

\section{Indicators of Effectiveness}

The following items were taken as indicators of effectiveness of Accelerated learning techniques:

\subsection{Classroom performance}

The students performed well in the tests, presentations and projects. The overall performance of the class was moderately above satisfactory.

\subsection{Participation in class}

The students actively participated in class activities. Humor and laughter punctuated group activities.

\subsection{Model company safety program assessment}

The students documented the safety program and practices of their selected model company. This was followed by an assessment of the comprehensiveness of the safety program based on the safety principles learned in class. A hazard analysis was also done on two critical processes. The reports were generally above satisfactory to outstanding.

\subsection{Adopted company new safety program}

The students' presentations of the new safety programs were generally well received by the invited representatives from the firm. Clarifications were made after the presentation.

\section{Conclusion}

The adoption of the principles of Accelerated Learning benefited the students in that they learned more, faster, and better, were able to apply what they learned in class in working on their projects, and became better and more creative innovators. Among the techniques used in the course, lectures using LCD projector has been weak in tapping a number of intelligences. This implies that although its use may lead to higher efficiency, the learner may find it difficult to be fully attentive, hence may not learn as much as expected. The use of the other techniques such as individual and group activities is more involving and fun to the students.

The learning facilitator noted that mapping out the intelligences for each instruction technique allows one to be more aware of the distinctions among the students with respect to their learning styles. If an instruction technique addresses most of the students' intelligences, then they learn much more at that span of time. Therefore, this is a practice that must be adopted by an accelerated learning facilitator in his pursuit of higher efficiency.

Without using AL techniques, learning facilitators could still be effective as long as they are able to catch the attention of the class through humor and fun and the use of multimedia. The learning facilitator must be open to learning from the students and 
should retain a sense of wonder that could be passed on to the students. In so doing, professional preparation becomes more thorough because it was more enjoyable than cumbersome.

\section{Appendix}

\subsection{Appendix 1}

Technique: Film showing of critical thinking concepts. A learning paper is submitted afterwards which is shared before the class, if time permits.

\begin{tabular}{|l|l|}
\hline Intelligence & Step in Exercise \\
\hline Interpersonal & The learners share the insights gained with the class. \\
\hline Logical & $\begin{array}{l}\text { There is a defined process. The time limit for the submission of } \\
\text { the paper adds structure. }\end{array}$ \\
\hline Spatial & $\begin{array}{l}\text { The film shown is visual and so is the presentation of a student in } \\
\text { front of class }\end{array}$ \\
\hline Musical & The film is enlivened with musical background. \\
\hline Linguistic & The written and spoken words are used. \\
\hline Intrapersonal & The learners think of what to document and write the paper alone. \\
\hline Kinesthetic & The learners write their learning paper. \\
\hline Emotional & Watching videos is fun. \\
\hline Naturalist & Weak \\
\hline Existential & $\begin{array}{l}\text { Learning about the effects of hazards on personal well-being } \\
\text { allows the learner to think of mortality which may somehow be } \\
\text { linked to thoughts of one's purpose in life.. }\end{array}$ \\
\hline
\end{tabular}

\subsection{Appendix 2}

Technique: Lectures with the aid of LCD projector

\begin{tabular}{|l|l|}
\hline Intelligence & Step in Exercise \\
\hline Interpersonal & $\begin{array}{l}\text { Some learners are given the chance to respond to questions posted } \\
\text { by the learning facilitator. }\end{array}$ \\
\hline Logical & The presentations are highly structured. \\
\hline Spatial & LCD projector is highly visual. \\
\hline Musical & Weak \\
\hline Linguistic & The spoken and written words are used. \\
\hline Intrapersonal & $\begin{array}{l}\text { Learners are given a chance to think through the lecture as it } \\
\text { proceeds. }\end{array}$ \\
\hline Kinesthetic & Weak \\
\hline Emotional & Watching videos is fun. \\
\hline Naturalist & Weak \\
\hline Existential & Weak \\
\hline
\end{tabular}




\subsection{Appendix 3}

Technique: Individual and Group Activities to facilitate learning (such as research of different styles and strategies of preparing arguments, as well everyday applications in communication media to gather, assess, record, and apply relevant information in architectural coursework.

\begin{tabular}{|l|l|}
\hline Intelligence & Step in Exercise \\
\hline Interpersonal & Learners share with team and with the class \\
\hline Logical & There is a defined process for each activity. \\
\hline Spatial & $\begin{array}{l}\text { Observing the different styles and strategies of arguments is } \\
\text { visual and so with the scrutiny of the documents. }\end{array}$ \\
\hline Musical & Weak \\
\hline Linguistic & The written word is used. \\
\hline Intrapersonal & $\begin{array}{l}\text { The student is provided some time to remember the different } \\
\text { styles in preparing arguments. }\end{array}$ \\
\hline Kinesthetic & Weak \\
\hline Emotional & Coming out with the output is fun. \\
\hline Naturalist & Weak \\
\hline Existential & $\begin{array}{l}\text { Talking with others about life events creates thoughts about } \\
\text { personal purpose. }\end{array}$ \\
\hline
\end{tabular}

\subsection{Appendix 4}

Technique: Study of a model company that could be benchmarked for safety program implementation. The students make visits to the company to obtain a document of safety program, witness its application, and evaluate it based on learning in class. A job hazard analysis of two processes is also conducted.

\begin{tabular}{|c|c|}
\hline Intelligence & Step in Exercise \\
\hline Interpersonal & The learners share with the team. \\
\hline Logical & $\begin{array}{l}\text { They are provided with the outline of the required report on } \\
\text { the Model Company, which defines the process }\end{array}$ \\
\hline Spatial & $\begin{array}{l}\text { Observing the different styles and strategies of arguments is visual } \\
\text { and so with the scrutiny of the documents. }\end{array}$ \\
\hline Musical & Weak \\
\hline Linguistic & The written and spoken word is used. \\
\hline Intrapersonal & $\begin{array}{l}\text { The learners delegate activities to each member of the team to } \\
\text { facilitate the process. }\end{array}$ \\
\hline Kinesthetic & The learners move about the plant as they observe. \\
\hline Emotional & Being accommodated by employees who are knowledgeable, is fun. \\
\hline Naturalist & It is good to have a tour of the premises of the plant. \\
\hline Existential & $\begin{array}{l}\text { Conducting a job hazard analysis which is useful for the model } \\
\text { company created thoughts about personal purpose }\end{array}$ \\
\hline
\end{tabular}




\subsection{Appendix 5}

Technique: Study of an adopted company, an SME. The new learning about safety management obtained in class discussions and from insights of model company is used to devise a safety program. The team presents the suggested safety program before a company representative and the learning facilitator.

\begin{tabular}{|c|c|}
\hline Intelligence & Step in Exercise \\
\hline Interpersonal & $\begin{array}{l}\text { The learners interview company personnel and share with team } \\
\text { the findings. }\end{array}$ \\
\hline Logical & The list of requirements for the project is highly structured. \\
\hline Spatial & The plant visit activity is highly visual. \\
\hline Musical & Weak \\
\hline Linguistic & Learners talk and share the spoken word. \\
\hline Intrapersonal & $\begin{array}{l}\text { The learners delegate activities to each member of the team to } \\
\text { facilitate the process. }\end{array}$ \\
\hline Kinesthetic & The learners move about as they observe. \\
\hline Emotional & Nurturing an adopted company \\
\hline Naturalist & It is good to have a tour of the premises of the plant. \\
\hline Existential & $\begin{array}{l}\text { Devising a useful safety program for the adopted company } \\
\text { creates thoughts about personal purpose. }\end{array}$ \\
\hline
\end{tabular}

\subsection{Appendix 6}

Technique: Presentation of particular topics by the students within the grasp and understanding of the class. Each team is given a topic to present before the class. The uses of role play, contests, video creation, and class involvement activity are all encouraged.

\begin{tabular}{|l|l|}
\hline Intelligence & Step in Exercise \\
\hline Interpersonal & There is high interaction between the presenters and the class. \\
\hline Logical & $\begin{array}{l}\text { The list of topics to be presented by each team provides a good } \\
\text { structure. }\end{array}$ \\
\hline Spatial & The presentation techniques as suggested are highly visual. \\
\hline Musical & Video films are accompanied by background music. \\
\hline Linguistic & The spoken word is used. \\
\hline Intrapersonal & $\begin{array}{l}\text { Each learner is given a chance to think through aspects of safety } \\
\text { alone as presentation proceeds. }\end{array}$ \\
\hline Kinesthetic & The class is involved with activities devised by presenters. \\
\hline Emotional & Each presentation is fun. \\
\hline Naturalist & Weak \\
\hline Existential & Weak \\
\hline
\end{tabular}




\section{References}

[1] H. Gardner and T. Hatch, "Multiple Intelligences go to School: Educational Implications of the Theory of Multiple Intelligences", Educational Researcher, vol. 18, no. 8, (1989), pp. 4-9.

[2] M. Kornhaber and H. Gardner, "Varieties of Excellence: Identifying and Assessing Children's Talents", A Series on Authentic Assessment and Accountability, New York, (1993).

[3] D. Lazear and David, "Teaching for Multiple Intelligences", Fastback 342 Bloomington, IN: Phi Delta Kappan Educational Foundation, (1992).

[4] W. C. Martin, "Assessing Multiple Intelligences", Proceedings of the International Conference on Educational, (1995).

[5] B. Tracy and C. Rose, “Accelerated Learning Techniques", Nightingale Conant Corporation, (1995).

[6] C. Rose and D. Rose, "Accelerated Learning", London, (1985).

[7] D. Meier, "The Accelerated Learning", Handbuch zum schnellen und effektiven Lernen in Gruppen, Bonn, (2004).

[8] H. Gardner, "Frames of Mind: The Theory of Multiple Intelligences", Basic Books, (1985).

[9] H. Howard, "Intelligence Reframed: Multiple Intelligences for the $21^{\text {st }}$ Century", Basic Books, (1999).

[10] H. Gardner, "Audiences for the Theory of Multiple Intelligences", The Teachers College Record 106, no. 1 (2004), pp. 212-220.

[11] E. H. Stefanakis, "Multiple Intelligences and Portfolios", Portsmouth, NH: Heinemann, (2002).

[12] T. Ganiron Jr, "Cultural Learning Environment and Perception of Structural Engineering Classes in Qassim University", World Scientific and Engineering Academy and Society (WSEAS) Transactions on Advances in Engineering Education Journal, vol. 9, no. 3, (2012) December 1, pp. 84-93.

[13] J. O'Connor and J. Seymour, "Introducing Neuro-Linguisting Programming", The New Psychology of Personal Excellence, (1989).

[14] A. Waitman, "Counseling and Psychotherapy", Psychotherapy and Mental Handicap, (1992), pp. 202.

[15] T. Ganiron Jr, "Student Competencies in Structural Engineering: Modeling Cultural Environment in Qassim University", Journal of Proceedings of the 40th Annual Conference of the European Society for Engineering Education (SEFI), (2012) September 23-26; Thessaloniki, Greece.

\section{Author}

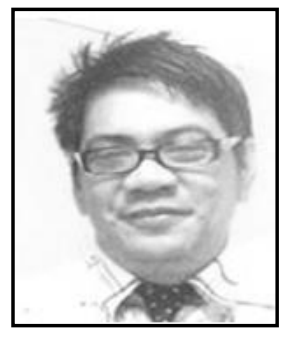

Tomas U. Ganiron Jr. This author obtained his Doctor of Philosophy in Construction Management at Adamson University (Philippines) in 2006, and subsequently earned his Master of Civil Engineering major in Highway and Transportation Engineering at Dela Salle University-Manila (Philippines) in 1997 and received Bachelor of Science in Civil Engineering major in Structural Engineering at University of the East. (Philippines) in 1990. He is a registered Civil Engineer in the Philippines and Professional Engineer in New Zealand. His main areas of research interest are engineering education, construction engineering, construction management, project management and recycled waste materials.

Dr. Ganiron Jr is a proud member of professional organizations like the Institution of Engineers-Australia and American Society of Civil Engineer. He is also very active in other professional groups like Railway Technical Society of Australasia and Australian Institute of Geoscientists where he became committee of Scientific Research. He has given invited or keynote lectures at a number of international conferences and has received the ASTM Award CA Hogentogler for 2008 in New Zealand and Outstanding Researcher for 2013 in Qassim University. 